\title{
Physical education and health as a child's right: Reflections on the Soweto Active Schools programme
}

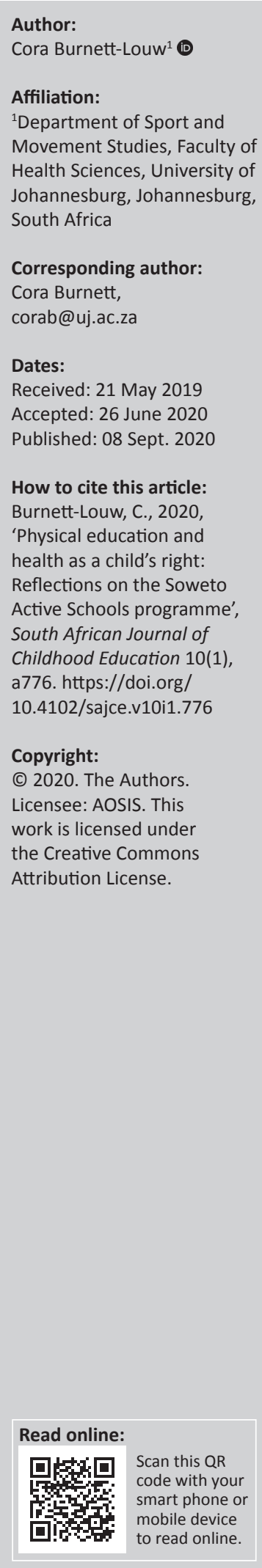

Background: In view of global health concerns about high levels of inactivity and related disease patterns of citizens, Physical Education and Health (PEH) has become an educational priority in many countries, including South Africa.

Aim: The research aimed to explore and capture the effects of a multistakeholder physical education (PE) initiative that focuses on in-service teacher training and implementation of the Soweto Active Schools programme.

Setting: The study was conducted in five pilot schools in Soweto, located in close proximity to the Nike Centre, where the schools take part in organised sport events as part of the programme.

Methods: This pre-post (2016 and 2018) multisite case study utilised mixed methods. Qualitative data were collected through observation of PE lessons, interviews with key stakeholder representatives $(n=6)$, five school principals $(n=10)$ and focus group discussions with life skill/life orientation heads of department and teachers $(n=59)$ and Grade 6 learners $(n=63)$.

Results: The main findings indicated the emergence of a new educational paradigm informed by value-based PE. Teachers reported positive behaviours by learners, whereas they applied the same values in the teaching of other classes. Learners reported the learning of new motor skills, improved social relations and improved confidence. Principals and teachers appreciated the scaled model of contextually relevant professional learning.

Conclusion: The model disputes the mere outsourcing of PE that elicits the participation of teachers will not adequately equip them for teaching PE. The model can be refined and taken to scale with meaningful information for curriculum design, resource provision and effective implementation of quality PEH.

Keywords: physical education; health; teacher; education; life orientation/life skills; children's rights; professional development, Soweto.

\section{Introduction}

Against a background of widespread poverty, countries like South Africa, as signatory to various international charters and pledges, have to deal with multiple societal problems (Ndebele 2017; United Nations Children's Fund [UNICEF] 2016). Governments are faced with much pressure to address wide societal issues within different public sectors. Global agencies such as UNICEF, the United Nations Educational, Scientific and Cultural Organisation (UNESCO) and the World Health Organization (WHO) drive accountability and adherence to a human justice and development agenda as captured by the 17 Sustainable Development Goals (SDGs) for 2030 (UNICEF 2017). These agencies mobilise governments to address global pandemics, such as the human immunodeficiency virus/acquired immunodeficiency syndrome (HIV/AIDS) crisis and more recently the obesity pandemic, through policy reform and alignment of national development plans (The Lancet 2019). In response, the African Union (AU) agreed on policy reform for physical education (PE) and school sport (PESS). At the first regional conference, branded as 'Regional Advocacy towards Sustainable Development of a Peaceful, Ethical, Healthy and Active Africa', held in Antananarivo in Madagascar from 10 to 13 September 2019, the Antananarivo Recommendations were adopted (Burnett 2020). The latter entail the mobilisation of resources and strategies for integrating sport, PE and physical activity (PA) in adherence to the 2017 Kazan Action Plan, and call for delivery on selected SDGs.

The high obesity rates in South Africa affect 7 out of 10 females and 4 out of 10 males, and an estimated $50 \%$ of children who do not meet the recommended physical activity requirements (Janssen et al. 2005). Most stakeholders turn to schools and invest in sport, PE and physical activity as possible low-cost solutions to address global and national health concerns (Micklesfield et al. 2014). 
The orginal Charter for PE, Physical Activity and Sport adopted in 1978 stated that the practice of PE and sport is a fundamental right for all (UNESCO 2013). The charter was amended in 1991 and responded to significant evolutions in the field by incorporating the Declaration of Berlin in 2013 at the 5th International Conference of Ministers and Senior Officials Responsible for Physical Education and Sport (MINEPS V) that was adopted by 600 participants from 121 countries (UNESCO 2013). In 2015, the charter was revised to ensure inclusive access to health-enhancing physical acitivity and informed the UNESCO drive towards quality PE (QPE) (UNESCO 2017a).

South Africa became a pilot country for UNESCO's QPE project in response to the MINEPS VI meetings and implementation of the Kazan Action Plan's three main policy areas. The latter emphasise quality PE and active schools, inclusive participation in sport, improvement of well-being and health and protection of vulnerable populations (UNESCO 2017b). Such proposed action speaks to the Health Kids South Africa 2018 Report Card, which indicates an increase in sedentary living (graded as F), and the fact that $32 \%$ of South African learners are not participating in PE or health-inducing physical activities (Draper et al. 2018). Such priorities emphasise the key role of PE proposed by the Department of Basic Education (DBE 2015). For instance, by prioritising UN agencies' drive for physical education and health $(\mathrm{PEH})$, the DBE launched a national research project on the state and status of PE in South African public schools (Burnett 2018). Other stakeholders joined forces to mobilise resources for related issues.

Nike International has been partner to the UNESCO inception of the QPE policy because the organisation rolled out their Designed To Move global initiative. Based on this initiative, Nike South Africa (Nike SA) implemented a PE programme in Alexandra Township, and since 2016 they have implemented the Soweto Active Schools programme in partnership with a non-governmental organisation (NGO) and the district authority of Gauteng Education. This fits their new global Make To Play strategy and represents an agency-driven configuration of partners to implement this global-local articulated initiative (DBE 2015). The scene is set for the current research, which informs the national research project on the role of partner collaboration in the primary school setting of Soweto - a township area where five lowerquintile schools shaped the pilot project.

The main aim of the article is to critically reflect on a multistakeholder PE pilot project as potential blueprint for upscaling in South Africa's public schools. This fills a gap in the existing literature to position a grassroots intervention against the human rights global and national architecture. The key learnings thus have bearing on stakeholder collaboration and inform strategic decision-making regarding $\mathrm{PE}$ teacher education (PETE) and an effective PE programme that would contribute to meaningful outcomes despite the lack of resources in lower-quintile schools.

\section{Conceptual framework}

There seems to be much contention regarding the conceptualisation of what QPE entails. Politicians and policy experts often make unsubstantiated claims about PE as a statutory entitlement to address or prevent deviant (and criminal) youth behaviour, develop responsible citizens and curb the obesity crisis (Coalter 2013). Broader societal issues are complex and difficult to measure, and causality is difficult to trace to specific interventions. These claims encapsulate the expectations of society and '[depend] on the beliefs, values, and aspirations that society develops about [them]' (Cloes 2017:245). Since the 19th century, societal needs have influenced the nature and educational outcomes of PE - from the hygienic phase of Swedish and German gymnastics (up to the 1960s), the sport-centred phase (from the 1970s to the new millennium) to the current focus on health outcomes (Cloes 2017; Kirk 2013). The latter phase represents the global strategic thrusts that found expression in an evolving paradigm of health-enhancing PE. It represents an educational framework that transcends the biomedical focus on health and fitness outcomes and advocates for a 'comprehensive but physically active approach that involves teaching social, cognitive, and physical skills, and achieving other goals through movement' (Sallis \& McKenzie 1991:126). The approach of holism finds expression in UNESCO's promotion of QPE, defined by AIESEP (2014):

[A]t any level, as that which concerns the physical, affective, social and cognitive development of young people, exposing them to positive individual and collective learning experiences where they develop knowledge, skills and dispositions that allow them to be informed and responsible decision makers relative to engagement in physical activity and sport in their lives. (p. 3)

At the core of societal expectations lies the essence of PE, which envisages children being exposed to physical activity, games and learning that may shape attitudes positively and foster knowledge for lifelong learning and healthy living with human movement as medium of learning (Stidder 2015).

Globally, a pedagogical model-based approach provides special focus on a range of learning outcomes, subject content and didactical approaches embedded in diverse philosophical arguments (Kirk 2013). Most prominent models counter the 'one-size-fits-all', narrow, sport-technique-based or multiactivity approaches, such as Sport Education, Physical Literacy or Movement Literacy (based on movement competencies), Teaching Games for Understanding, Cooperative Learning, Personal and Social Responsibility and Health-based PE (Kirk 2013). Another model gaining traction is the concept of physical literacy, relevant to the fields of public health, recreation, sport and (physical) education (Dudley et al. 2017).

Issues of conceptual clarity around the term 'literacy' still need to be resolved as they relate to the levels of proficiency determined by different assessment regimes, associations 
with functionalism (and universalism) and being embedded in social settings (Dudley 2015). Various hybrid models have emerged in an attempt to capture the essence of competencybased physically active living (Aggerholm et al. 2018). Key strategies allow for contextual adaptation and acknowledge subjectivity (child-centred approaches), provision of meaningful challenges (needs appropriation), content and aims (appropriateness and interest), specifying and negotiating standards of excellence (diversified and scaled) and providing adequate practice time (for multidomain skill mastery and application) (Aggerholm et al. 2018; Dyson, Kulinna \& Metzler 2016).

Trained teachers are pivotal in delivering quality PE practices in primary school, as the childhood years are 'increasingly critical to developing a foundation of lifelong physical activity and health' (Atencio, Jess \& Dewar 2012:129). As curricular reform of $\mathrm{PE}$ in various contexts necessitates the continuing professional development (CPD) of teachers, scholars increasingly criticise the ineffective top-down model, where teachers are perceived as 'empty vessels' receiving content and pedagogical knowledge out of context from an external expert (Dyson 2014). In traditional models, teacher training represents a mechanistic educational paradigm based on prescribed (rigid) planning and prescribed standards as outcomes, and quality teaching focuses on holism rather than adhering to loyalty to a curriculum (Dyson 2014). Effective, in-context and job-embedded teacher-training models are found in the SHAPE and STARK programmes (the United States [US]) (Dyson 2014; Tian, du Toit \& Toriola 2017) and Basic Moves (Scotland) (Atencio et al. 2012). The SHAPE America curriculum focus on constructivist teaching practices aimed at delivering behavioural change among teachers and learners, so as to foster and broaden experiences and learning beyond skill performances (Butz 2018). Such models show effects in addressing the non-teaching practices of untrained and unskilled (classroom) teachers, taking into account the competency levels and needs of teachers within a multistakeholder (nested) setting (Atencio et al. 2012; Fletcher et al. 2018). Another development entails the outsourcing of health-enhancing PE as a form of edu-business delivered by external agencies to schools (Sperka \& Enright 2018). This trend has found traction in South Africa, where civic society actors (NGOs and volunteers) offer PE and/or school sport at poorly resourced public schools (Burnett 2018, 2020).

Contextual embeddedness in training practices is crucial for impactful teacher education and learning in South African public schools, where they are confronted by inadequate resource provision and a narrow assessment-focused curriculum (Stroebel, Hay \& Bloemhoff, 2018; Van Deventer 2012). Walter (2014) discusses a low-cost intervention that effectively promotes the provision of PE in disadvantaged schools in South Africa, and thus demonstrates contextual relevance and application. This mitigates against what Dyson (2014:148) refers to as the 'mindless approach to physicality', where untrained teachers focus on 'narrow assessments' without providing teaching for attitude change and knowledge application that could transfer into real-life settings and lifelong learning (Karasimopoloulou, Derri \& Zervoudaki 2012). This article reports on a non-linear contextually embedded and collective training model implemented in the Soweto Active Schools initiative.

\section{The programme}

In 2014, Nike South Africa implemented the Alex Butterflies programme, which is a local programme that is an outcome of the global Designed to Move initiative - a physical activity action agenda proposed by influential global organisations such as Sport NIKE, Inc., the International Council of Sport Science and Physical Education (ICSSPE) and the American College of Sports Medicine (Burnett \& Hollander 2014). The curriculum design and implementation are guided by the seven prescribed Designed to Move filters that relate to universal access, health-inducing dosage and duration, age appropriateness, provision of incentives and motivation, provision of fun and positive feedback and facilitation of optimal learning through teaching, coaching and mentorship (Nike 2012).

After the 2016 pre-intervention evaluation, Nike SA redesigned the programme and implemented it as the Soweto Active Schools programme in collaboration with the Department of Education Gauteng and five primary schools located in close proximity to the Nike Football Training Centre in Soweto. The programme intended to link the PE component of the life skills (Foundation and Intermediate Phase) and life orientation (LO) (Senior Phase) curricula with school sport events that form part of the programme.

The programme contained four pillars, namely, PE during school hours, inter and/or intraclass and interschool competition and the integration of youth leadership and life skill development via a value-based education approach (Burnett \& Hollander 2018). The purpose of the programme was to increase the physical activity of learners during and after school, utilising PE as catalyst. In achieving this outcome, it focused on providing support and training (workshops and in-service training) to LO teachers to aid the implementation of PE in the school context and offer intra- and interschool events. The implementing NGO, contracted by Nike SA, offered an orientation workshop to principals and selected two 'champion' teachers per school, followed by a 5-day training workshop during the school holidays in 2016.

Schools arranged their timetables in order to accommodate the programme for one day per week. Two trained facilitators from the NGO presented the programme on certain (agreedupon) days and times at the different schools. The schools each chose a certain day for programme implementation, and the programme implementers referred to the schools by the day of service delivery, such as 'the Monday school'. Initially, the NGO facilitators delivered $80 \%$ of the classes, with teachers delivering $20 \%$, after which the responsibility and roles shifted over a period of three years to ensure transfer of ownership to the teachers by the end of the third year. It was 
a prerequisite that all teachers should attend all the classes presented or partially presented by the external service providers. The latter were available for consultation and assisted implementing teachers beyond class presentations. In turn, the champion teachers assisted and, to some extent, mentored other teachers in their respective schools.

Over the three years, more teachers presented classes and accepted the intended transfer of ownership from the external service provider, referred to as 'outsourcing to the school' (insourcing). Within the cluster of five schools, one interschool competition per term took place at the Nike Football Centre, which is within walking distance from all the schools. The progress differed between schools and teachers, with the ones who attended the direct trainings being relatively better equipped, as well as those schools where teachers worked within a cluster system to support one another.

\section{Research design and method}

The qualitative study reported here forms part of a pre-post pathway formative analysis of the implementation of the PE programmes in five primary schools as part of the Soweto Active Schools programme, in which an external service provider presented $80 \%$ of the PE classes in 2016, 50\% in 2017 and $20 \%$ in 2018. This phased approach translated into teachers receiving on-site and additional trainings to take full responsibility for teaching PE to their classes. The instrument forms part of the S.DIAT (Sport-in-Development Impact Assessment Tool), which also utilises mixed methods for programme evaluation and determining programme effects (Burnett 2018). Full details of the evaluation are provided by Burnett and Hollander (2018).

At the onset of the programme in 2016, pre-intervention data were obtained from principals, heads of department (HODs), teachers and learners regarding their perceptions, experiences and the implementation of $\mathrm{PE}$ at their respective schools. These pre-intervention results were compared to data obtained from the same cohorts of research participants in 2018. However, for this research report on qualitative data gathered from adult study participants and Grade 6 learners in 2016 and 2018, the latter cohort was selected, for the reasons noted below.

\section{Sample}

All five principals, sport masters and two NGO facilitators involved in delivering or managing the programme agreed to participate in the research. In turn, the principals identified HODs and teachers for interviews and/or focus group discussions. The purposive sample composed of decisionmakers (principals), HODs and teachers representative of all the phases in the primary school (Foundation Phase, Intermediate Phase and Senior Phase). The research participants within the pre-post design included all school leadership and teachers who volunteered their time and Grade 6 learners because of their language proficiency and ability to retrospectively report on their experiences and perceptions. A whole class was randomly collected to complete questionnaires, after which a teacher would identify focus group participants ('easy talkers') as a purposive sample. However, the questionnaire data are not reported in this article. The sample for qualitative data per research method at school level included the following:

- Focus group with Grade 6 learners: $n=63$ (30 in 2016 and 33 in 2018), which entailed a total of 10 different focus group sessions at the five schools during the pre- and post-interventions; the size of focus groups varied between four (two boys and two girls) and eight (four boys and four girls) learners taking part at a given session

- Interviews with principals or deputy principals: $n=10$ (5 in 2016 and 5 in 2018)

- Interviews/group discussions with HODs: $n=18$ ( 9 each in 2016 and 2018)

- Interviews/group discussions with teachers: $n=41$ (17 in 2016 and 24 in 2018).

Key decision-makers represented all five schools as principals or deputy principals who took part in face-to-face interviews and provided information on policy, structures, practices and programme implementation. Related questions were also packaged for focus group discussions (for teachers and learners) to obtain a contextual understanding of the programme expectations, experiences and effects. The following questions were asked during interviews and focus groups and adapted for principals, HODs and teachers before, during and after the intervention.

\section{Pre-intervention phase}

- What is your philosophy/approach towards PE within your school?

- How do you implement PE within the school/grade/ class?

- What would you consider is working well (good practices) relating to the implementation of PE in your school?

- What are the main challenges of implementing PE in the school/grade/class?

- Tell me about the Soweto Active Schools programme in your school. (Probe recruitment, training, implementation and stakeholder involvement.)

- What expectations do you have in terms of the outcomes of the Soweto Active Schools programme?

\section{Post-intervention phase}

This phase composed retrospective reflections on questions 1-5. Question 6 asked about the outcomes related and unrelated to the initial expectations in terms of what they perceived to be the benefits of the Soweto Active Schools programme for the school, the class, teachers and learners (collectively and personally).

Consensus information across different break or differential characteristics (e.g. age and gender) was obtained from learners recruited to take part in focus group discussions. 
Heads of department from the Intermediate and Senior School phases were nominated by the principal, and in turn they recruited teachers to take part in focus group discussions or interviews. A purposive sample and multiple means of triangulation ensured data saturation, as similar questions were put to all research participants (Creswell 2013). Multiple means of triangulation contribute to significant depth, reliability, validity and trustworthiness, which in this study was addressed through mixed methods (interviews, focus groups, document analysis and observation), multiple settings (five schools), different times and spaces and two researchers (Teddlie \& Tashakkori 2011).

The two senior researchers attended two meetings with representatives from the District Office of the Department of Education, schools, NGO and Nike SA, followed by interviews in 2016 and 2018 with the two NGO coaches and the Nike SA representative. The qualitative data thus informed the contextual understandings that underpin the explorative and descriptive nature of the study, rather than tracing programme causality effects.

\section{Data collection and analysis}

Two researchers and assistants visited five schools during the day as the programme was implemented, lessons were observed and pictures taken of the facilities and lessons. One researcher was predominantly responsible for collecting qualitative data, assisted by a translator. These research visits commenced with the research team explaining the purpose and nature of the research to the principals, discussing the content of all methods and assuring them that a teacher could be present at all times. The principal and HOD determined the research day procedures to ensure minimal disruption of school activities. This included observation of a PE lesson, as the research visit took place on 'implementation day'.

The researcher used the coding steps emanating from the work of Strauss and Corbin (1990) by firstly sorting and categorising the raw units into significant units of meaning, from which concepts emerged. Then, line-to-line coding delivered concepts through comparison and the identification of the cause-effect relationships. The concepts were then semantically grouped through axial coding to connect subcategories or themes. These categories were refined further (selective coding) to identify the core categories or main themes with semantically related subthemes (Creswell 2013).

\section{Ethical considerations}

The research formed part of a national research project on the state and status of physical education in South African public schools in search of an example of in-service teacher training and external service provider involvement. The research received ethical clearance from the University of Johannesburg, Faculty of Health Science Ethics Committee (H16-HEA-HMS-008), and served broad ethical issues in addition.
Two researchers and assistants visited five schools during the day when the programme was implemented; lessons were observed and pictures taken of the facilities and lessons. One researcher was predominantly responsible for collecting qualitative data, assisted by a translator. These research visits commenced with the research team explaining the purpose and nature of the research to the principals, discussing the content of all methods and assuring them that a teacher could be present at all times. The principal and HOD determined the research day procedures to ensure minimal disruption of school activities. This included observation of a PE lesson, as the research visit took place on implementation day.

Analysis of all the qualitative data followed the coding procedures, comparative member checking and theme generation as prescribed by Creswell (2013:185). It included processes to ensure the trustworthiness, validity and reliability of the study through triangulation of the data from different research participant cohorts, multiple researchers, different methods (interviews, observation, focus groups and document analysis) and interpretation. The inductive approach was merged with the deductive categorisation of themes obtained from the literature study to inform the final themes, reported as findings from documents, data sets obtained from teachers and principals and findings from learners.

\section{Results and discussion The curriculum}

The Soweto Active Schools curriculum design shows high coherence with the PAMIA principles of QPE as discussed by Cloes (2017:248):

P: Foster play/pleasure - provide meaningfulness and increase pleasure

A: Foster achievement and learning - individualise goals and set challenges

M: Foster movement - create activities and situations for active movement

I: Foster interaction - increase contact with others and the environment

A: Foster autonomy - provide students with opportunity for decision-making.

The principles are well aligned with the Designed to Move filters and focus on the transferability of knowledge, skills and attitudes that would extend beyond school hours and foster lifelong active behavioural habits. Schools are viewed as 'open societies' to facilitate a synergy between societal and individual perceptions of quality of life as meaningful formative outcomes. 'Living values' associated with positive social behaviours (respect, cooperation, communication and an ethic of care) are embedded in various modular frameworks, curricula and didactical approaches (Karasimopoloulou et al. 2012).

The sport-to-life approach is well aligned with the principles relating to positive interaction (I), movement facilitation (M) and meaningful participation in enjoyable physical activity $(\mathrm{P})$. 
Large classes, lack of adequate resources and didactical flexibility hamper individual goal achievement and the fostering of autonomy and learner input for joint decisionmaking. The imaginative slogans of the sport-to-life philosophy capture the teaching and learning of associated values by giving expression to them in different experiences. These slogans entail:

- Use your voice

- Come to play

- Stay in the game

- Build your team

- Look, listen and learn

- Plan, (have) goals and prioritise. (Interview with Sportstec director on 05 September 2018 and a follow-up interview on 28 March 2019)

The focus on value education dominated most focus group discussions, with positive perceptions of how values are incorporated in their teaching of different subjects. The values translated into meaningful life lessons for some learners:

'We like the learnings like "stay in the game", "build the team", "show respect", "use your voice" - this helped us in the school. There is now less bullying even if the teacher does not go outside.' (Learner, focus group, September 2018)

'Some activities are hard, but we should stay and participate and support each other. In maths, you sometimes get angry when you do not know how to calculate, but you have to stay in the game until you get the answer.' (Learner, focus group, September 2018)

A few teachers mentioned that they applied these values as mothers (at their homes), whilst most learners indicated that they used them for motivation and to inspire them to persevere, speak up, collaborate and positively interact with peers. Learning and practising these values changed the way they viewed others and made them become more compassionate and accepting of others as they are.

Value education based on local norms and life views encapsulates what Cloes (2017) refers to as societal expectations. The child-centred approach and cross-curricular relevance of the learning ensure that these values and understandings contribute to a school-wide motivational climate, as advocated by Aggerholm et al. (2018) and Dyson et al. (2016). It transcends the mechanistic educational paradigm criticised by Dyson (2014) by allowing for application in different settings (Dyson et al. 2016). For learners, the approach mostly translated into changed behaviours during PE lessons, where they were included, collaborated with others and found acceptance. For teachers, it was mainly about encouraging learners to persevere (stay in the game) and transfer these values to their home environment and loved ones.

\section{Teacher education and programme implementation}

The facilitators from the local NGO obtained the relevant qualifications for implementing PE and offered a variety of activities based on thorough planning and continuous assessments as prescribed by the Curriculum Assessment Policy Statement (CAPS). They applied the 80-20 principle for transferring the implementation of the programme, taking the lead $(80 \%)$ and gradually transferring the responsibilities of planning, implementation and assessment to the teachers, who after three years should be able to lead. Heads of department and teachers reported that the in-context training and programme implementation afforded the learners the opportunity to master fundamental motor skills and actively participate in games and teams. In this regard, the model of training is supported by job embeddedness, as found in highprofile global programmes such as SHAPE and STARK (Dyson 2014), as well as Basic Moves (Atencio et al. 2012).

In 2016, the facilitators took most of the practical lessons; they changed over time, and in 2018, a new culture of participation spread within and among the participating schools. Some teachers and HODs said that they took leadership by offering mentorship and convening at cluster meetings. They created a forum to advance knowledge and share experiences that could aid in-school mentorship between the teachers who had gone for training and others who did not attend the workshop. Such mentorship practices support active learning and capacity building among teachers, as evidenced in a constructivist view of teacher education, as it describes real-life programme implementation practices and causality of effects (Butz 2018).

Teachers reported that the initial success for them was being able to draw up lesson plans and implement different activities increased. During focus group discussions, most teachers stated that they still needed more training, especially about the technical aspects of skill acquisition, age-appropriate adaptation of activities, planning and methodology. Most valued their own progress and experienced a sense of success and satisfaction, as expressed in these narratives collected in September 2018:

'We got lesson plans and were very happy about it. We learnt how to select activities. It is working. In the past, we were confused, but now we have a clear understanding.' (Principal, interview)

'Before the programme, the learners will just participate for fun. But now, the programme is well planned and we have objectives - they developed us as teachers. ... Before we could not put it into practice, but now we know how to do it. We got ideas and templates. We got rubrics for assessment.' (Teacher, focus group)

Most teachers who attended the initial training workshop were relatively positive about learning new technical skills that they could implement in their own classes, which also enhanced their knowledge base and level of confidence. A principal explained the narrow and assessment-focused approach prior to the current programme implementation:

'I [principal] am teaching Grade 7 myself and also take them for Life Orientation. I do not know techniques to teach ... I go with them, and they show me the techniques. Even the children will tell you [how to perform the skills]. I did not use the period before, as they do now. I would have the lesson in front of me and then 
tell them to jump through the hula-hoops. The programme was just to assess the activities, and I will give them the tasks to practise. The activities depended on what was in the textbook ... We have never received any training for Life Orientation. I remember what my coach taught me and then would do the same kind of thing.

Now, it is a different story and even teachers do not complain about the lack of time or burden of having too many administrative duties. We are all motivated, and even other principles talk to us and ask us if they can also be part of the programme. Teachers now are more interested in assisting with (sport) coaching as well.' (Principal, interview)

In 2016, most teachers cited various obstacles to being able to implement PE practical classes, such as inadequate knowledge, skills, limited time allocation and administrative load. Atencio et al. (2012) and Fletcher et al. (2018) emphasise the importance of effective teacher education and skill development as key resources for the implementation of PE. For South African academics, the lack of qualified teachers remains a key obstacle for implementing any kind of $\mathrm{PE}$ or health-related physical activities (Stroebel 2018; Van Deventer 2012).

\section{Programme implementation and effects}

The implementation of the programme necessitated timetable changes to ensure that in-service training could dovetail with curriculum requirements. One principal explained:

'Arranging the school's timetable to have all physical education (PE) classes on a particular day, in itself added to the status of the learning area. The visibility of having a dedicated PE and/or sports day in itself changed perceptions.' (Principal, interview)

All learners who took part in focus group discussions in 2016 had a very positive attitude towards the 'new way of doing physical education', in terms of its inclusiveness, new content (warming up and cooling down), as well as the child-centred approach:

‘Previously we did not do a proper programme. It was just some exercises and assessments per term. Now the whole class takes part. We do different exercises and learn skills.' (Learner, focus group - 2016)

All the learners reported that they learnt a variety of physical activities that introduced them to different sports and afforded them the opportunity to play with their peers. The inclusiveness of the programme across age (different grades and age-appropriate activities) and gender (boys and girls) ensured that all learners were given the opportunity to be active and take part in PE:

'Last year we raced with our partner and the teacher would give us marks when we went to the ground. Not all children were playing, and only the teams were called to practise. We can make friends with other children in our class - playing together.' (Learner, focus group, 2018)

The children said that they enjoyed the variety of activities and sport skills that contributed to a keen interest for some to participate in sports after school. The fact that facilitators brought some equipment for programme implementation was essential for the mastery of sport-related skills and to have 'more than one ball' that allowed them to practise. This, in turn, attracted the interest of principals, who would assist in purchasing some equipment. In one case, the principal obtained external funding (R7500.00) to purchase balls and other items for use in the programme and for the after-school sport programme.

The attractiveness of playing in regular competitions is not only an extension of the educational outcomes, but affords learners the opportunity to compete, which is an inherent part of sport (Burnett 2018). Integration and synergy occurred between theory and practice (PE and life skills/ LO) and between the latter and school sport. The sport events offered at the Nike Centre provided opportunities for all classes to participate in sport-related events. In this way, there was a direct link between the sessions and the intraschool or intergrade competitions for which teams are chosen to give learners the opportunity to take part in various events like the mini-Olympics (first term), 5-a-side sport (second term), as well as football and netball leagues (third term). The teams represent groups of mixed ability levels to be as inclusive as possible. The participants communicated positive sentiments:

'We mostly play at home when we play against other teams. It is very nice to play at the stadium [Nike Centre], then we can go there and meet other children.' (Learner, focus group, September 2018)

The close proximity of schools in the programme to the Nike Centre made it possible for the children to attend events. Competing and cooperating in and between teams afford children the opportunity to play with their peers, make friends, support team members and show sportsmanship, whilst it created a pathway from PE to sport participation. Karasimopoloulou et al. (2012) and Cloes (2017) documented the principles of QPE and sport participation by showing living values and the creation of inclusive opportunities that facilitate active learning and living.

All learners who participated in focus group discussions found the classes enjoyable and meaningful. Teachers and learners expressed the perception that PE classes afforded them the opportunity to discover which activities learners excelled in and in that sense assisted them in identifying their talents:

'Then you take those [slow learners] out and you break that isolation. They get their time to shine in $\mathrm{PE}$, and they come to enjoy school. They will even remind you the day before that "tomorrow we have to go out, it is PE".' (Teacher, September 2018)

'I now play more with friends. Running is my thing - it is my talent. PE makes me realise that I can run. I go running now four times per week.' (Learner, focus group, September 2018)

The learners were very enthusiastic about taking part in the programme; as a result they usually came to school on time and looked forward to taking part in physical activities 
during school hours. Children enjoy learning new skills and applying them in game and play settings that set performance and social challenges (Aggerholm et al. 2018).

In 2016, a teacher organising sports at his school (sport master) also stated that there was less absenteeism on the days that the programme took place. In 2018, most teachers made a similar observation and stated that the programme allowed those learners who would 'be loafing' or 'bunking school, to attend school regularly as they like the programme and can show their talent'. This illustrates that the programme served as a positive 'hook' that would motivate children to attend school (Stidder 2015).

The popularity and meaningfulness of the programme, associated with positive experiences, carries such value that teachers used it as an incentive. There seemed to be an increase in sport participation, and teachers were positive about the spillover effects of the programme:

'Children enjoy the activities, and more children are now interested in sport - we have a $\mathrm{u}$ [under] $/ 11, \mathrm{u} / 12$ and $\mathrm{u} / 13$ team. First, we could not find enough players; now we have two teams per age group ... Now of late, the children compete in their right age groups, and there is not the thing of injuring each other.' (Teacher, focus group, September 2018)

Holding such events and allocating a specific day for all classes to have PE practical lessons contributed to the recognition of the potential importance and value of the subject within the school context. In this way, inclusive sport practices contributed to an enabling environment with potential positive educational outcomes (Janssen et al. 2005; Micklesfield et al. 2014).

New sport interests were cultivated, and girls especially wanted to engage in different sporting activities:

'Mass participation in sport happened, and more learners now participate in soccer competitions ... Girls only played netball before; now they also play soccer, and they learn other sport skills as well. More children now take part in sports. Even the shy kids have become more playful and are jumping about.' (Principal, interview, September 2018)

'Before, the boys mainly played soccer during the PE periods. Now we have learnt to play indigenous games, and we play netball.' (Learner, focus group, September 2018)

For most learners, taking part weekly in a variety of activities and having the opportunity to compete in teams and attend sport events at Nike Stadium added to their sense of belonging (to a team and school); it led to self-discovery (of their talents and preferences) and broke down gender stereotyping, as girls were able to compete in traditionally male sports like soccer. For teachers, the offering of regular, enjoyable and meaningful PE contributed to positive educational outcomes, such as improved school attendance, theory-practice integration within PE and increased school sport participation that was status-conferring to the school when they competed against other schools at a prestigious venue.

\section{Holistic development through physical education}

In the baseline report, the assessments as prescribed by CAPS were the main directive, and although limited, $40 \%$ of teachers indicated that they mostly 'taught for assessments' (Burnett \& Hollander 2018). At the baseline assessment, the majority of teachers mostly implemented assessments without prior teaching, but expected the programme to have positive educational outcomes such as prosocial behaviour and improved concentration in other classes. They also anticipated that the programme would improve the confidence levels of learners and address the matter of bullying - stopping or decreasing such behaviour.

With the change in educational philosophy and approach, teachers commented that doing the prescribed assessments was not problematic (anymore), and they could take a holistic approach towards teaching and application across the curriculum. The holistic nature of teaching and learning found traction in daily living and demonstrated a meaningful ripple effect towards real-life applications. Principals related narratives that spoke to the educational focus and benefits for the schools, teachers and learners:

'They are attached to the Life Orientation teachers. We also talk about the values during assembly ... When we have break from ten to eleven a.m., there used to be a lot of fighting. We start with the smaller ones to give them food, but then the bigger children got into mischief. Now they play the games and they can finish eating in 20 minutes. They are active and they do not break the toilets anymore. They just eat, then go, and play.' (Principal, interview)

'Before, children were too scared to talk. Now they are using their voices ... Now we use life skills and we did not have an idea ... [In] PE we talk life skills, and now I teach them English and history, like about fighting, and remind them of sport-for-life skills. You lose a lot if you cannot solve a problem.'

They learn language in a practical way. When they now go into the class and you ask them to write on the black board, they can follow the instruction, and they are less shy to act in front of the class.' (HOD, focus group)

During interviews and focus group discussions, the teachers were the most vocal about the impact of value education. This demonstrates a paradigm shift from teaching to education and participative learning evident in an ethic of care. The teachers were more aware of the learners' individual needs and identified differential change that contributed to particular programme outcomes. In a small but significant way, the change towards holistic educational practices is in line with global (UNESCO 2013, 2017a, 2017b), national (DBE 2015) and local (Stroebel 2018; Tian et al. 2017) trends in good practices. The very nature of QPE resides in a comprehensive strategy, transferability of learning and interdomain (development) articulation (Karasimopoloulou et al. 2012; Sallis \& McKenzie 1991; UNESCO 2017b).

Part of the comprehensive and interdomain educational outcomes is positive interaction and social skills development. 
During a focus group discussion in September 2018, a teacher said that learners opened up and accepted one another:

‘[...E]specially children who are bullied and make other people see what they are doing. At the beginning of the year, they would laugh if somebody makes a mistake, but now they do not laugh anymore if the answer is wrong. They correct them in a good manner.

Learners are now better at group work and work together to build their team (a value). They do not abuse others by using their voice correctly .... (Teacher, focus group, September 2018)

We became confident and independent. The programme makes me energetic. We play the games in the school, and then we play it with our friends at home. My mother likes the indigenous games.' (Learner, focus group, September 2018)

These narratives demonstrate the interest of learners and the worth they find in learning new activities and values that they can apply in school and at home. In this way, the programme broadened the scope of participation and created positive interactions with significant others and peers (Stidder 2015).

The perspectives and observations of principals and teachers were particularly meaningful in their similarity and nuanced articulation across the different school settings. The qualitative data support the former observation of 'perceptions of value' regarding $\mathrm{PE}$ as expressed by all research participant cohorts. This result was obtained despite the dire lack of sport facilities and the inadequate amount and quality of equipment, as combined classes (up to 80 learners) may have 'two balls borrowed from the coach' with which to play. The low socioeconomic status of local households further compromised the purchasing of exercise or sport clothing, particularly footwear for winter or for special surfaces. The lack of these key resources compromised the effective implementation of the programme and the promotion of 'mass school sport participation' (Draper et al. 2018; Stroebel, Hay \& Bloemhoff 2018 2018; Walter 2014).

\section{Conclusion}

On examining the findings thoroughly, several recommendations could be directed towards different stakeholders within the current configuration. Firstly, there is consensus that the DBE in collaboration with other national departments (e.g. Ministry of Sports, Arts and Culture) should jointly address the lack of physical and qualified human resources. In collaboration with universities and educational institutions (including the NGO sector), in-service educational programmes should transcend traditional once-off events to constitute an authentic and contextual learning environment supported by mentors composed of external agencies and expertise within and between schools. Several school principals were of the opinion that training and knowledge exchanges between facilitators should take place within a specific cluster, where some skilled staff can act as mentors and cascade knowledge down to the local, interschool level.

This proposed modification to the existing programme agrees with other low-cost interventions (Walter 2014) and suggested
PETE approaches advocated by Stroebel et al. (2018). This approach is similar to the job-embedded teacher training models implemented in the US for the SHAPE and STARK programmes (Dyson 2014), as well as for Basic Moves in Scotland (Atencio et al. 2012). The difference lies in the type of service provider, which in this case is a local NGO that offers on-site training over a 3-year period in collaboration with a funder (Nike) and the Department of Education at the district level (Burnett \& Hollander 2018). This multi-year partnership and sharing of resources countered the traditional outsourcing model in PE by building sustainable in-school capacity (Burnett 2018; Sperka \& Enright 2018).

The success of such a programme is highly dependent on an enabling environment in which the support of the school leadership (particularly principals) and the school governing body (SGB) are important. Primary school learners' participation in PE classes and sport events is dependent on the provision of practice clothing, permission to take part in after-school programmes and attendance of parents at sport events. School governing body members have a key role to play in promoting learners' right to participate in active sport play and informing other parents of the potential value of such active participation and supportive parenting. Promotional material may be jointly generated by different partners and capitalise on the Nike (sport) branding of schools and of the programme. Nike South Africa may continue to play a key negotiating role in mobilising agencies for teacher education according to the Soweto Active Schools model and, by doing that, promote QPE and Designed to Move principles and knowledge.

The current programme needs some modification before it can be implemented at other schools. Various challenges should be addressed, such as managing large (gender-mixed) classes and limited time allocation by adapting the didactics and having more (well-trained) teachers involved in the teaching. Physical education teacher education should be supplemented by teachers qualifying in the coaching of different sports. Lessons learnt from the PETE model include that more teachers should attend special workshops, followed by supportive structures and mentorship at the school and cluster levels. Resource provision in terms of upgrading existing school-based facilities and a dedicated budget (from DBE) to purchase good quality equipment and pay for transport would assist schools to compete in other school sport leagues. The school leadership and SGB members should be involved in fundraising and mobilise parents to support their children in active participation in PESS. Curricular reform is necessary to accommodate and promote the integration of PESS, as well as guide integration between the school and the community.

A valuable angle for future research would be to explore innovative in-service teacher training models and strategies to enhance the quality of PE teaching in South African public schools. It would be particularly valuable to investigate feasible options for PETE in contexts of poverty. Focused research in stakeholder engagement and partnerships from a 
critical and pragmatic perspective should translate into actionable recommendations for meaningful transformation through and within PE.

\section{Limitations}

This study had some limitations as a result of collecting data from primary school learners over a 3-year period. The required language proficiency and ability to reflect on their experiences in PE necessitated the recruitment of learners from higher grades, but because of the duration of the research and for pre-post comparison, only the data obtained from Grade 6 learners were utilised. At two schools, learners experienced difficulty expressing themselves in English, and the researchers were dependent on the facilitators or teachers for translations, which may have affected learners' comments on the quality of teaching.

The reported differences contributed by the programme were not evaluated in comparison to other interventions. The validation of findings in terms of improved motor skill proficiency necessitates other evaluation protocols that fell outside the scope of this particular study but would have added a valuable dimension to the research.

\section{Acknowledgements}

The author thanks Nike South Africa in partnership with Sportstec and the District Office of Education, in addition to the principals and staff who provided access and participated in the research.

\section{Competing interests}

The author declares that no competing interests exist.

\section{Author's contributions}

C.B.L. is the sole author of this research article.

\section{Funding information}

Nike SA funded the evaluation, but a more in-depth investigation was self-funded.

\section{Data availability statement}

Data sharing is not applicable to this article as no new data were created or analysed in this study.

\section{Disclaimer}

The views expressed in this article belong to the author and do not represent the position of the institute or any other organisation affiliated with the author.

\section{References}

Aggerholm, K., Standal, O., Barker, D.M. \& Larsson, H., 2018, 'On practising in physical education: Outline for a pedagogical model', Physical Education and Sport Pedagogy 23(2), 197-208. https://doi.org/10.1080/17408989.2017.1372408
AIESEP, 2014, 2014 AEISEP position statement on physical education teacher education, viewed 11 January 2019, from https://aiesep.org/wp-content/ uploads/2014/11/2014-AIESEP-Position-Statement-on-Physical-Eduationuploads/2014/11/2014-

Atencio, M., Jess, M. \& Dewar, K., 2012, 'It is a case of changing your thought processes, the way you actually teach: Implementing a complex professional learning agenda in Scottish physical education', Physical Education and Sport Pedagogy 17(2), 127-144. https://doi.org/10.1080/17408989.2011.565469

Burnett, C., 2018, National research: The state and status of physical education in public schools of South Africa, UNICEF, Pretoria.

Burnett, C., 2020, State and status of school sport in public schools of South Africa, UNICEF, Pretoria.

Burnett, C. \& Hollander, W.J., 2014, The impact of the Nike South Africa running programme, University of Johannesburg, Department of Sport and Movement Studies, Johannesburg.

Burnett, C. \& Hollander, W.J., 2018, Post-implementation study of the Soweto Active Schools Programme, Nike South Africa, Johannesburg.

Butz, J.V., 2018, 'Applications for constructivist teaching in physical education', Strategies 31(4), 12-18. https://doi.org/10.1080/08924562.2018.1465868

Cloes, M., 2017, 'Preparing physically educated citizens in physical education: Expectations and practices', Retos: Nuevas Tendencias en Educación Física, Deporte y Recreación 31(1st Semester), 245-251.

Coalter, F., 2013, Sport for development. What game are we playing?, Routledge, London.

Creswell, J.W., 2013, Research design: Qualitative, quantitative, and mixed methods, Sage, Thousand Oaks, CA.

Department of Basic Education (DBE), 2015, DBE gets moving on physical education viewed 08 May 2019, from https://www.education.gov.za/DBEgetsmovingon PhysicalEducation.aspx.

Draper, C.E., Tomaz, S.A., Bassett, S.H., Burnett, C., Christie, C.J., Cozett, C. et al., 2018 'Results from South Africa's 2018 report card on physical activity for children and youth', Journal of Physical Activity and Health 15(suppl 2), S406-S408. https://doi. org/10.1123/jpah.2018-0517

Dudley, D.A., 2015, 'A conceptual model of observed physical literacy', The Physical Educator 72(5), 236-260. https://doi.org/10.18666/TPE-2015-V72-15-6020

Dudley, D.A., Cairney, J., Wainwright, N., Kriellaars, D. \& Mitchell, D., 2017, 'Critical considerations for physical literacy policy in public health, recreation, sport, and education agencies', Quest 69(4), 436-452. https://doi.org/10.1080/00336297.20 16.1268967

Dyson, B., 2014, 'Quality physical education: A commentary on effective physical education teaching', Research Quarterly for Exercise and Sport 85(2), 144-152. https://doi.org/10.1080/02701367.2014.904155

Dyson, B., Kulinna, P. \& Metzler, M., 2016, 'Introduction to the special issue: Models based practice in physical education', Journal of Teaching in Physical Education 35(4), 297-298. https://doi.org/10.1123/jtpe.2016-0203

Fletcher, T., Lodewyk, K., Glover, K. \& Albione, S., 2018, 'Learning to become instructional coaches in health and physical education', Journal of Teaching in Physical Education 37(4), 313-321. https://doi.org/10.1123/jtpe.2018-0024

Janssen, I., Katzmarzyk, P.T., Boyce, W.F., Vereecken, C., Mulvihil, C., Roberts, C. et al., 2005 , 'Comparison of overweight and obesity prevalence in school-aged youth from 34 countries and their relationships with physical activity and dietary patterns', 34 countries and their relationships with physical activity and dietary patterns',
Obesity Reviews 6(2), 123-132. https://doi.org/10.1111/j.1467-789X.2005.00176.x

Karasimopoloulou, S., Derri, V. \& Zervoudaki, E., 2012, 'Children's perceptions about their health-related quality of life: Effects of a health education-social skills program', Health Education Research 27(5), 780-793. https://doi.org/10.1093/ program,
her/cys089

Kirk, D., 2013, 'Educational value and models-based practice in physical education', Educational Philosophy and Theory 45(9), 973-986. https://doi.org/10.1080/001 31857.2013.785352

Micklesfield, L.K., Pedro, T.M., Kahn, K., Kinsman, J., Pettifor, J.M., Tollman, S. et al., 2014, 'Physical activity and sedentary behavior among adolescents in rural South Africa: Levels, patterns and correlates', BMC Public Health 14, 40. https://doi. org/10.1186/1471-2458-14-40

Ndebele, T., 2017, 'Education', in F. Cronje (ed.), South Africa survey 2017, pp. 459-580, Institute of Race Relations, Johannesburg.

Nike, 2012, Designed to move: A physical activity action agenda, viewed 09 May 2019, from https://www.eupea.com/designed-to-move-a-physical-activity-action-agenda/.

Sallis, J.F. \& McKenzie, T.L., 1991, 'Physical education's role in public health', Research Quarterly for Exercise and Sport 62(2), 124-137. https://doi.org/10.1080/027013 67.1991.10608701

Sperka, L. \& Enright, E., 2018, 'The outsourcing of health and physical education: A scoping review', European Physical Education Review 24(3), 349-371. https:// A scoping review, European Physical Ed
doi.org/10.1177/1356336X17699430

Stidder, G., 2015, Becoming a physical education teacher, Routledge, London.

Strauss, A. \& Corbin, J., 1990, Basics of qualitative research: Grounded theory procedures and techniques, Sage, Newbury Park, CA.

Stroebel, L.C., Hay, J. \& Bloemhoff, H.J., 2018, 'Challenges facing life skills and life orientation subject advisors in implementation of physical education', South African Journal for Research in Sport, Physical Education and Recreation 40(3), 121-136.

Teddlie, C. \& Tashakkori, A., 2011, 'Mixed methods research: Contemporary issues in an emerging field', in N.K. Denzin \& Y.S. Lincoln (eds.), The SAGE handbook of qualitative research, 4 th edn., pp. 285-300, Sage, Thousand Oaks, CA. 
The Lancet, 2019, The global syndemic of obesity, undernutrition, and climate change: The Lancet Commission Report, viewed 26 April 2019, from https://doi. org/10.1016/S0140-6736(18)32822-8

Tian, H., Du Toit, D. \& Toriola, A.L., 2017, 'The effects of an enhanced quality physical education programme on the physical activity levels of Grade 7 learners in Potchefstroom, South Africa', Physical Education and Sport Pedagogy 22(1), 35-50. https://doi.org/10.1080/17408989.2015.1072509

United Nations Educational, Scientific and Cultural Organisation (UNESCO), 2013 MINEPS V - 2013, viewed 26 April 2019, from https://www.unesco.org/new/en/ social-and-human-sciences/themes/physical-education-and-sport/mineps$2013 /$.

United Nations Educational, Scientific and Cultural Organisation (UNESCO), 2017a Promoting quality physical education policy, viewed 08 May 2019, from https:// www.unesco.org/new/en/social-and-human-sciences/themes/physicaleducation-and-sport/policy-project/.
United Nations Educational, Scientific and Cultural Organisation (UNESCO), 2017b, MINEPS VI - KAZAN 2017, viewed 08 May 2019, from https://en.unesco.org/ mineps6/kazan-action-plan.

United Nations Children's Fund (UNICEF), 2016, The state of the world's children 2016 A fair chance for every child, UNICEF, New York, NY.

United Nations Children's Fund (UNICEF), 2017, Generation 2030. Africa 2.0. Prioritizing investments in children and reap the democratic dividend, UNICEF, New York, NY.

Van Deventer, K.J., 2012, 'School physical education in four South African provinces: A survey', South African Journal for Research in Sport, Physial Education and Recreation 34(1), 153-166.

Walter, C.M., 2014, 'Promoting physical activity: A low cost intervention programme for disadvantaged schools in Port Elizabeth, South Africa: Physical activity', African Journal for Physical Health Education, Recreation and Dance 20(21), 357-371. 